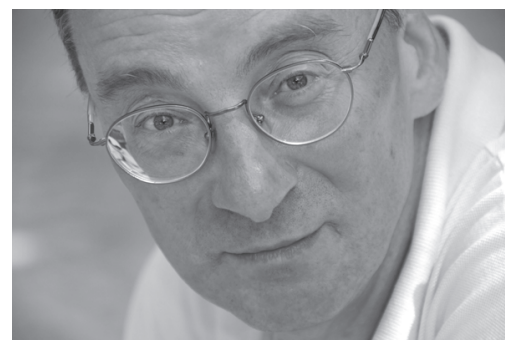

\title{
Strukturen fördern
}

Die Individualisierung, so sagen es uns Soziologen und Historiker, ist ein Kennzeichen der Moderne. Der Mensch, so der französische Philosoph JeanPaul Sarte, sei zur Freiheit verurteilt. Er könne nicht nur sein Leben frei gestalten, er müsse es. Auch in der Wohlfahrtspflege ist die Entscheidungsfreiheit des Einzelnen immer mehr in den Mittelpunkt gerückt worden. Unter dem Begriff der »Personenzentrierung " wird versucht, nicht den Menschen den Angeboten anzupassen, sondern die Hilfen je individuell zu gestalten. Schon früh gab es an dem Begriff und dem Konzept eingehende Kritik. Es sei verboten, Personen zu zentrieren, formulierte der Sozialpsychiater Klaus Dörner seine Meinung zum vorherrschenden Trend der Konzentration auf den Einzelnen. Es gehe nicht um das Handeln »am Individuum«, sondern um eine humane Gestaltung von Beziehungen im größeren Zusammenhang seines Umfeldes. Die bessere Alternative zur Institutionszentrierung sei deshalb nicht die Personenzentrierung, sondern die Gemeindezentrierung. Der Mensch lebt nun mal nicht im leeren Raum, seine Defizite, seine Ressourcen und seine Beziehungen zu anderen gelte es, in den Blick zu nehmen. Alles deutet darauf hin, so Stefan Blank in seinem Einleitungsbeitrag zu diesem Heft, dass die einrichtungszentrierten Entwicklungswege an einem Wendepunkt angekommen seien und nun der Pendel in die andere Richtung zurückschlage. Die neuen Ziele von Inklusion und Personenorientierung geben die Marschrichtung vor. Politik und Verbände, Leistungsträger und Dienstleistungserbringer sollten dabei immer bedenken, dass es nicht um isolierte Hilfen geht, sondern um Ermöglichung von Eigeninitiative und um die dazu erforderliche Gestaltung von Beziehungen zwischen Institutionen und Menschen. Wie das Beispiel des Persönlichen Budgets zeigt, können individuelle Hilfen sich nur entfalten, wenn die dafür förderlichen Strukturen geschaffen und erhalten werden, beispielsweise hinsichtlich von Beratung und Assistenz.

Gerhard Pfannendörfer, Chefredaktion pfannendoerfer@nomos.de www.sozialwirtschaft.nomos.de 